\title{
ENTREVISTA COM AMINA Di MUNNO
}

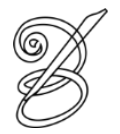 \\ Davi Silva Gonçalves ${ }^{1}$ \\ Doutorando em Estudos da Tradução \\ (PGET - UFSC - Florianópolis - Brasil) \\ goncalves.davi@hotmail.com \\ William Franklin Hanes ${ }^{2}$ \\ Doutorando em Estudos da Tradução \\ (PGET - UFSC - Florianópolis - Brasil) \\ hanes.wf@gmail.com
}

mina Di Munno é professora de língua e literatura portuguesa na Universidade de
Gênova (Itália), atuando também como tradutora de textos literários em inglês e
português. No que concerne à sua pesquisa acadêmica a professora Di Munno se dedica principalmente não só à obra de autores mais canônicos como Fernando Pessoa, Machado de Assis e Eça de Queiroz como também daqueles mais contemporâneos, como o próprio Milton Hatoum (cujos títulos em português foram por ela vertidos para o italiano). A entrevista a seguir foi resultado da disciplina intitulada “Tradução Literária”, ministrada por ela e por Andréia Guerini na Pós-Graduação em Estudos da Tradução da UFSC no ano de 2013.

1. Em entrevista à revista Cadernos da Tradução no início deste ano (2013/1 $\left.{ }^{3}\right)$ você fala sobre uma "relação mútua de respeito e amizade" com o escritor Milton Hatoum. Poderia falar um pouco sobre o que pensa acerca do autor e sobre sua experiência não só com ele, mas também com as suas obras que você traduziu até aqui?

AMINA DI MUNNO: Conheci a obra antes que o escritor Milton Hatoum, aliás conheci o primeiro romance, Relato de um Certo Oriente, que traduzi a pedido da Editora Garzanti. O encontro com o escritor aconteceu na cidade de Milão durante a apresentação do livro ao público italiano. Naquela ocasião fomos convidados ambos, autor e tradutora, por parte da Editora, e o momento marcou o início de uma amizade e de uma colaboração fundada sobre uma relação, por parte do autor (acredito que seja assim!) de confiança, e do meu lado, de 
admiração profunda pela escrita e pelos conteúdos originais, que fui redescobrindo nas obras sucessivas de Milton Hatoum, obras que tive ainda oportunidade de traduzir. Em todos os romances, Milton fala de seu mundo de contrastes, de conflitos familiares e históricos com o dom da palavra que nele se faz poesia e se veste de mistério e magia.

2. Acredita ser importante que um tradutor aprecie e se alinhe ideologicamente ao trabalho daquele autor que se propõe a traduzir? Até que ponto?

AMINA DI MUNNO: É, sem dúvida, pelo menos na minha experiência pessoal, importante apreciar o trabalho do autor que me proponho a traduzir, pois terei a responsabilidade de interpretar, decodificar e recodificar a obra para chegar ao metatexto. Deverei construir uma ponte hermenêutica entre uma língua e outra, uma cultura e outra. Com o autor terei que estabelecer um conjunto de operações de síntese, de compreensão, de mediação entre o seu mundo e o meu, para além do seu posicionamento ideológico. A este respeito, todavia, 216 acredito que quanto mais próxima esteja a sua ideologia em relação ao pensamento do tradutor, menos significativos resultarão os limites do traduzir, posto que é impossível pensar em conseguir um resultado perfeito, ideal.

3. A escrita de Milton Hatoum se destaca por uma linguagem híbrida e bastante específica ao local Amazônico a qual é, muitas vezes, incompreendida mesmo dentro do Brasil dependendo da região onde se encontram seus leitores. Como lidar com esse fenômeno durante o processo tradutório?

AMINA DI MUNNO: No diálogo que o tradutor estabelece com o autor existem situações em que dificilmente as reformulações na língua de chegada conseguem manter o mesmo domínio expressivo, a mesma complexidade metafórica, as mesmas conotações empregadas pelo autor. Quanto à linguagem específica da Amazônia, a meu ver, a melhor solução é a de recorrer ao auxílio de um bom dicionário monolíngue e de utilizar, quando possível, um termo que, conforme a teorética tradutória, poderíamos definir interpretativo. Na impossibilidade de encontrar outro tipo de “negociação”, é meu costume recorrer ao uso do glossário, traduzindo para o italiano a explicação que o dicionário monolíngue me oferece. 
4. Descreva, em termos gerais, seu posicionamento com relação à tradução literária e/ou científica entre os seguintes dois polos: adequação (do seu texto) tendo em vista o texto fonte ou aceitabilidade (do seu texto) tendo em vista a cultura de chegada.

AMINA DI MUNNO: Acredito que não seja possível estabelecer uma total polarização no sentido formulado, o trabalho do tradutor é principalmente uma ação de mediação, que implica uma fidelidade ao prototexto, sem que isto signifique traduzir "palavra por palavra", mas resolvendo as dificuldades que, sinteticamente, costumamos definir transculturais. É significativo lembrar que Steiner, em sua ampla concepção do ato de traduzir, definiu a tradução “uma experiência existencial”. De uma maneira geral, não só ao traduzir a literatura de Hatoum, acredito que os dois conceitos não se excluem. In media res: respeito e fidelidade ao original e fluência no texto de chegada são os dois elementos em direção dos quais tende uma boa tradução.

5. Acredita que seu posicionamento nestes pontos também seria aplicável (aconselhável) para outros tipos de tradução (e.g. científica, etc.)?

AMINA DI MUNNO: A tradução literária apresenta peculiaridades codificadas pelos translation studies. Trata-se da elaboração de um processo de recodificação, que implica um fluxo dinâmico e dialógico entre um texto e outro. Não acontece assim, a meu ver, em outros tipos de tradução, principalmente na tradução técnica, cujas características e especificidades são de diferente natureza. A tradução técnica é uma tradução especializada. O tradutor deverá ter conhecimentos específicos em determinadas áreas e transmitir de forma clara a mensagem do texto original, mas não terá que lidar com a poética e o complexo universo intertextual aos quais a tradução literária reenvia.

\section{Onde se estabelece a fronteira entre tradução e adaptação?}

AMINA DI MUNNO: Na minha experiência como tradutora nunca pensei em realizar uma adaptação, pois considero os dois conceitos, tradução e adaptação, relativamente distantes, se bem que interlacionados. Cito a este respeito uma nota de Monica Longobardi, em que ela 
afirma: "È acquisito [...] che nella sfera di quanto si include entro il perimetro della traduzione cadano operazioni quali anche riscrittura, parodia, trasposizione fino all'adattamento. In relazione a questa evoluzione, i cosiddetti translation studies hanno spostato il loro centro di interesse da intenti prevalentemente prescrittivo-normativi a propensioni piuttosto analiticodescrittive delle traduzioni possibili”. (Monica Longobardi, Tradurre il Satyricon, in Testo a Fronte 40, 1 semestre 2009, IULM, Milano, p. 112). No meu entender, a adaptação define de preferência uma tradução intersemiótica.

7. Em que sentido(s) (se quaisquer) é o tradutor também um autor?

AMINA DI MUNNO: Vale lembrar que a profissionalização e a especialização da tradução, e me refiro principalmente à tradução literária, têm levado a figura do tradutor a assumir um papel de destaque compatível com a responsabilidade assumida e com a visibilidade do texto. Em uma entrevista ao escritor José Saramago, o jornalista português José Rodrigues dos 218 Santos fez-lhe a seguinte pergunta: “Quando estamos a ler uma obra traduzida, estamos a ler o autor ou o tradutor?” A resposta de Saramago, como frequentemente acontecia em suas conversas, de pessoa irônica e humilde, surpreende: "Eu creio que antes que chegue a essa tradução, já houve outra que é a do próprio autor. O autor é um tradutor.” No meu parecer, quanto a mim pelo menos, o tradutor não é um autor, mas um intérprete. Um exemplo sobre o qual concordo plenamente foi dado pelo filosofo Franco Volpi, que certa vez comparou a tradução de uma obra com a execução de um texto musical, afirmando que, se formos procurar as sensações do original do Requiem de Mozart, jamais as encontraremos, pois o que eu escuto é von Karajan ou algum outro diretor de orquestra, que executa e interpreta aquele original.

8. No romance Dois Irmãos (2000, p.61), quando no original Milton Hatoum narra que "O Calisto, um curumim meio parrudo do cortiço dos fundos, cuidava dos animais dos Reinoso, sobretudo dos macacos, que guinchavam e saltitavam nos imensos cubos de arame do quintal” na sua tradução do romance, Due Fratelli (2005, p. 52), você escreve: “un curumim mezzo infido, del cortiço del retro, badava agli animali dei Reinoso, soprattutto alle scimmie, che strillavano e saltavano negli enormi cubi di rame del giardino”, logo mantendo a palavra 
curumim também na versão traduzida. Poderia falar especificamente sobre essa escolha em itálico?

AMINA DI MUNNO: A escolha de manter o termo curumim no texto de chegada, assim como cortiço e vários outros, é devida à falta de uma palavra que traduza exatamente, com as mesmas conotações, aqueles termos para o italiano. Esta dificuldade justifica a necessidade de recorrer ao glossário que acompanha a tradução.

9. Já na página 63 do romance de Hatoum o narrador fala sobre as filhas do personagem Talib: “Eu tinha a impressão de que eram incansáveis, não podiam ficar paradas um só minuto, faziam tudo na casa e ainda ajudavam o pai na taberna” (Dois irmãos, 2000). Em sua versão a palavra taberna é traduzida como ristorante: “Avevo l'impressione che fossero instancabili, non stavano ferme un solo minuto, facevano tutto in casa e aiutavano anche il padre nel ristorante” (Di Munno, Due Fratelli, 2005, p. 53). Poderia falar especificamente sobre essa escolha?

AMINA DI MUNNO: Neste caso, a escolha é devida ao contexto. Em italiano a palavra ristorante, num sentido geral, resulta ser sinônimo, ao contrário do português, de osteria, taverna, tavola calda, trattoria. Julguei que o termo pudesse compreender todas essas nuances. Na região onde vivo há um restaurante cujo nome é: "Ristorante la Vecchia Taverna”.

10. Quando o narrador Nael destaca a beleza de Zahia ao dizer que ele "devorava o quibe cru sem tirar os olhos das pernas cruzadas de Zahia, cobertas de pêlos dourados” (Hatoum, Dois irmãos, 2000, p. 63), você traduz o mesmo momento da forma seguinte: "Io divoravo le polpettine crude senza togliere gli occhi dalle gambe incrociate di Zahia, velate di una peluria dorata” (Di Munno, Due Fratelli, 2005, pp. 53-54). Poderia falar especificamente sobre essa escolha em destaque?

AMINA DI MUNNO: Em italiano a palavra peli, apesar de dourados, remeteria a um significado negativo, o oposto da feminilidade. Para destacar a beleza feminina, peluria é um termo mais apropriado. 
11. No romance de Hatoum Nael reclama das ordens de Zana, entre estas ordens estão a que segue: "Quando as casas da rua explodiam de gritos, Zana me mandava zarelhar pela vizinhança, eu cascavilhava tudo, roia os ossos apodrecidos dos vizinhos” (Hatoum, Dois irmãos, 2000, pp. 62-63). Em sua versão o trecho é traduzido como "Quando le case della strada scoppiavano dalle grida, Zana mi mandava a curiosare nel vicinato, io indagavo ovunque, scoprivo gli altarini dei vicini” (Di Munno, Due Fratelli, 2005, p. 54). Poderia falar sobre essa escolha em específico?

AMINA DI MUNNO: Trata-se de uma expressão idiomática, similar a scheletri nell'armadio, calco do inglês a skeleton in the cupboard.

12. No romance, repleto de relações familiares muitas vezes beirando o incestuoso, o narrador destaca a relação curiosa estabelecida entre os pais e filhos observados por ele. 220 Nael nota, por exemplo, com relação as filhas de Talib, que "quando elas dançavam, Talib lagrimava de gozo, sua barriga tremia de tanto prazer” (Hatoum, Dois Irmãos, p. 64). Em sua tradução o trecho é colocado da seguinte maneira: “Ma quando loro danzavano, Talib piangeva di allegria, la sua pancia tremava dal piacere” (Di Munno, Due Fratelli, 55). Poderia falar sobre a escolha da palavra allegria?

AMINA DI MUNNO: Creio que o sentido erótico permaneça inalterado na forma italiana, através da expressão la sua pancia tremava dal piacere. Por outro lado, não é comum na língua de chegada a expressão piangere di godimento, mas sim piangere di gioia, di allegria.

13. Existe mais algum aspecto que gostaria de destacar com relação à sua tradução desta obra de Hatoum?

AMINA DI MUNNO: Gostaria de acrescentar poucas reflexões sobre a importância para um tradutor de traduzir uma obra bem escrita. Em relação aos romances de Milton vai toda a minha admiração. Sua linguagem é depurada, cristalina. Suas palavras acompanham rigorosamente as exigências do contar. O seu estudo da linguagem facilita o trabalho do 
tradutor, que examina o texto desde uma posição de fronteira e procura adequar àquela versão a sua própria. Conseguir este objetivo, se é que alguma vez o tenha conseguido, foi sempre minha preocupação maior.

RECEBIDO EM: 18 de dezembro de 2014

ACEITO EM: 20 de janeiro de 2015

\footnotetext{
${ }^{1}$ Currículo lattes Davi Silva Gonçalves. Disponível em: http://lattes.cnpq.br/4264535213871108

${ }^{2}$ Currículo William Franklin Hanes. Disponível em: http://lattes.cnpq.br/5710028292619217

${ }^{3}$ https://periodicos.ufsc.br/index.php/traducao/article/view/2175-7968.2013v1n31p275/25017
} 